CHAPTER 2

\title{
From Logical Calculus to Logical Formality: What Kant Did with Euler's Circles
}

Huaping Lu-Adler

\section{r. Introduction}

John Venn, in his monumental Symbolic Logic, laments the lack of progress in mathematical logic between J. H. Lambert and George Boole and expresses an "uneasy suspicion" that it was due to Kant's "disastrous effect on logical method," the effect being the "strictest preservation [of logic] from mathematical encroachment." There is some truth to this speculation. In a way, Kant did want to preserve logic from mathematical encroachment. He was not entirely averse to the use of mathematical tools in logic, however. So his objection to mathematics encroaching on logic cannot be a straightforward call for banishing all mathematical devices from logic. Rather, as a knowing reader of Kant would suspect, the objection must have primarily to do with certain philosophical considerations about the very nature of logic and its relation to mathematics. The question is what such considerations might be.

Without aiming at a complete answer to this question, my primary goal in this chapter is to situate the question itself in a historical context where it may be investigated in a philosophically fruitful manner. Specifically, I consider what the mathematical encroachment upon logic - as a historical happening - might look like from Kant's perspective, what conceptual tools he might invoke to counter it, and what room he might still leave for mathematics in logic. To this end, I examine his use of circles in logic in comparison with Leonhard Euler's (as the most likely source of the former). I treat both uses of the circle notation as episodes of a broader narrative of how the project of logical calculus, as G. W. Leibniz first envisioned it, fared in eighteenth-century Germany.

${ }^{2}$ Venn, Symbolic Logic, pp. xxoiv-xoxvi. 


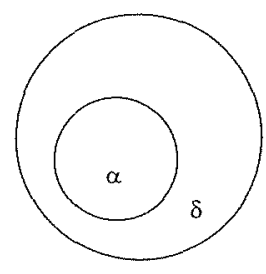

(c)

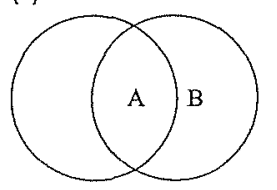

Figure 2.c. Some A is B.

(d)

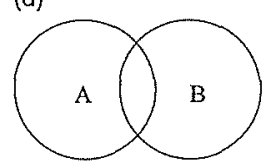

Figure 2.d. Some A is not B.

Figure 2.a. Every $\mathrm{B}$ is $\mathrm{A}$

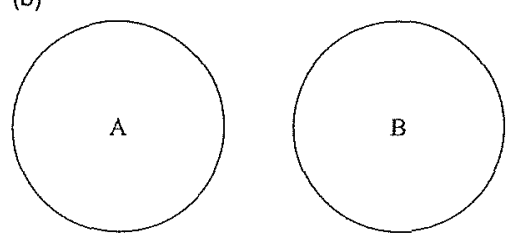

Figure 2.b. No $A$ is $B$.

\section{Preliminaries}

Kant uses circles (and occasionally squares) to represent logical relations between concepts in judgments and inferences. Here are three kinds of examples.

(i) Figure I represents the schematic relation between two concepts in a categorical judgment in abstraction from its quantity and quality: the subject, represented by the inner circle, is subordinate to the predicate, represented by the outer circle. ${ }^{2}$

(ii) Figures 2.a through 2.d represent the four basic forms of categorical judgments. ${ }^{3}$

${ }^{2} \mathrm{R}$ 3216, 16:716; see R 3096, 16:658; JL, 9:108.

${ }^{3}$ R 3215, 16:715; R 3036, I6:627; R 3063, 16:637. (a)

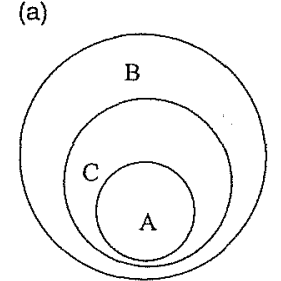

Figure 3.a. All $C$ is $B$, all $A$ is $C$; therefore, all $A$ is $B$. Or: $A$ ll $A$ is $C$; all $C$ is $B$; therefore, some $\mathrm{B}$ is $\mathrm{A}$.

(b)

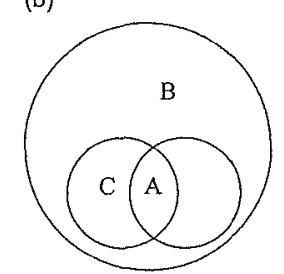

Figure 3.b. All $C$ is $B$; some $A$ is $C$; therefore, some $A$ is $B$.

(iii) Circles can also represent relations among the three terms in a categorical syllogism (Figures 3.a, 3.b). ${ }^{4}$

What shall we make of these diagrams? Are they meant, as Carl Prantl says of the "ingenious invention" of circle diagrams, merely to visualize

${ }^{4} \mathrm{R} 3215,16: 716$. 
certain relations of concepts so as to facilitate "the training of stupid heads"? Or is there something deeper at play? Kant does not say. But we can gather his answer from various materials: yes, there is something deeper at play.

Two kinds of materials are relevant here. One pertains to Kant's conception of logical formality, which sets the philosophical parameters for his treatment of logical notations. The other involves the historical context in which he adopted the circle notation. I begin with the latter.

Euler is often deemed the first to have used the circle notation, in his Letters of Euler to a German Princess (written during 1760-2). ${ }^{6}$ Although some historians have pointed out even earlier uses of circles (or similar figures) in logic, Euler's was Kant's most likely source. ${ }^{7}$ More importantly, as I shall explain, there are good reasons to see Euler's use of the circle notation as a conscious choice in an intellectual milieu where leading mathematicians and logicians were intrigued by, passionately engaged in, or otherwise cautious about the project of logical calculus, of which the design of mathematically exact logical notations was a critical part. Euler did not directly address the philosophical issues raised by such a project, but Kant would. Scrutinizing their respective uses of the circle notation will give us an opportunity to puzzle out their different positions in this respect.

Before I pursue this line of thought, a methodological note is in order regarding how to assess Euler's philosophical influence on Kant. Though primarily a mathematician and physicist, Euler wrote a fair amount on philosophical topics, most notably on the essence of matter and the nature of space and time. ${ }^{8}$ Commentators are divided over how to interpret his relation with philosophy. By one estimate, Euler was, at best, "incidentally" productive in philosophy: "Euler's philosophizing is in a very special way a dispute with other authors' philosophies. There is no peculiarly 'Eulerian' philosophical question, no special problem worrying or torturing him." On a contrary reading, Euler perhaps alone deserves the high

5 Prant, Geschichte der Logik im Abendlande, vol. I, p. 362.

${ }^{6}$ The first volume, which contains the letters that interest us here, was published in 1768 (Lettres à tune princesse d'Allemagne, St. Petersburg). References to the Letters are to letter numbers and pages of the English translation by Hunter (1795).

${ }^{7}$ On uses of geomerrical diagrams in logic before Euler, see Ueberweg, System der Logik und Geschichte der logischen Lehren, p. 216; and Venn, Symbolic Logic, pp. 504-9. Leibniz used them in two of his 1686 manuscripts, De formae logicae comprobatione per linearum ductus ("On Proving Logical Forms by Drawing Lines") and Generales inquisitiones de analysi notionum et veritatum ("General Inquiries about the Analysis of Notions and Truchs"). But neither manuscript was published until 1903.

8 Breidert, "Leonhard Euler and Philosophy," pp. 98-106. O Ibid., pp. 97-8. merit of "hustling the philosophy of the mid-I8th century out of an impasse by provoking discussions." Ao Although this is likely an overstatement, Euler played a pioneering role at least in eighteenth-century philosophy of science. In this regard, he is sometimes portrayed as a philosophically minded scientist who made concerted efforts to construct a physics in accordance with his "scientific metaphysics," with respect to which he was no less a philosophical "system-builder" and "concept-

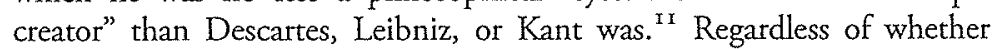
this comparison to Descartes et al. is apt, Euler's staunch defense of the Newtonian view on the relation between metaphysics and natural philosophy evidently impressed Kant.

To illustrate, here is a well-known case. In an article entitled "Reflexions sur l'espace et le tems" ("Reflections on Space and Time") (written in 1748 but printed in 1750 ), Euler argues that metaphysics as the study of the nature and properties of body must agree with the already established truths of mechanics, so that metaphysical ideas that lead to conclusions contrary to these truths must be rejected. Following this principle, he repudiates the Leibnizian-Wolffian relational theory of space and time in favor of the Newtonian conception of absolute space and time as that which undergirds the laws of mechanics. Referring to Euler's article, Kant agrees that in order for metaphysical inquiries about space and time to stay "on the path of truth," they must be founded on "reliably established data" such as those furnished by the "mathematical observation of motion, combined with [geometrical] cognition of space." Along these lines, he commends Euler's effort to prove the independent reality of absolute space a posteriori "by employing other indisputable propositions ... lying outside the realm of metaphysics" as opposed to "employing the most abstract judgments of metaphysics." In the meantime, however, Kant also finds the proof in question seriously inadequate and proceeds to offer his own. ${ }^{13}$

This case points to a nuanced philosophical relation between Kant and Euler. Simply put, if some of Euler's works raised important philosophical issues but he did not go far enough with them, Kant could take his suggestive insights as starting points for digging deeper. From Kant's

ro Fellmann, "Leonhard Euler - Ein Essay über Leben und Werk," p. 73.

"I Elkana, "Scientific and Metaphysical Problems: Euler and Kant," pp. 283 and 286.

"NM, 2:168. For a comparison of Kant's and Euler's views on the relation between metaphysics and physics, see Laywine, Kant's Early Metaphysics and the Origins of the Critical Philosophy, pp. 27-3x

${ }^{13}$ and 50. 
viewpoint, we may then appreciate

the philosophical significance of which mightively what Euler had to offer, or overlooked. Meanwhile, to which might otherwise be underestimated osophizing may be seen as an whatever extent Euler's "incidental" philitions on a given subject, a retrospement with other philosophical posnarrative unity into an array of pective appraisal may bring a degree of originality of Kant's stance may such positions, in reference to which the

With this general picture of their philose clear for the first time. ${ }^{\text {I }}$ ground, I now proceed to compare philosophical relation in the backnotation. I first examine Euler's ure Euler's and Kant's uses of the circle brief history of the Euler's use by treating it as but one chapter in Lambert, a history that will reveal bo logical calculus from Leibniz to ing this project and the highl both the technical challenges confrontphilosophical ideas $\left(\$_{3}\right)$. I then explain how nature of its underlying the Leibnizian idea of logical calculus, how Kant, who explicitly opposes circle notation from notion of logical formality $\left(\$_{4}\right)$.

\section{Euler's Circles and the Project of Logical Calculus}

When Euler introduces circles in the Letters to represent the four basic form eye" and thereby provide "a stated purpose is to "exhibit their nature to the distinctly wherein the accuracy of a chance towards comprehending more circles, or rather these spaces, for a chain of reasoning consists." 5 "These of, are extremely commodious for facilitating importance what figure they are and for unfolding all the boasted facilitating our reflections on this subject difficult to explain; whereas, by mysteries of logic, which that art finds it so sensible to the eye" (Letter CIII means of these signs, the whole is rendered figurative use of circles as helpful . 454). If these remarks suggest a merely Euler does not stop at that. He goes on to our logical comprehension, representing all propositions by claim that the method of of all syllogisms." of circles: they are means for demonstrating be called a proof-theoretical use A couple of historicing syllogisms.

circle notation. Friedrich Ueberwents paved the way for this use of the 4 For of them. One is that

\footnotetext{
und Euler."
Letter CII, pp. 452-3. $\quad{ }^{16}$ Letter CIII, p. 457 .
}

"the authority of the Aristotelian methods of reduction had been broken," and the other is "the inclination of that age toward mathematical treatment of logic, which among other things paid homage to Leibniz." "77 That is, by the time Euler wrote the Letters, it was no longer deemed possible to prove every syllogism by reducing it to a universal syllogism in the first figure. Instead, there must be common principles by which to prove any given form of syllogism as valid or invalid. ${ }^{18}$ The mathematical treatment of logic in a way answered this need. Leibniz was the first to employ both algebraic and geometrical means to represent propositions and demonstrate syllogisms. Although he did not publish his results, his conception of logical calculus was evidently known to the community of German intellectuals who were more or less acquainted with the underlying philosophical ideas. It was a community to which Euler was intimately connected.

To be specific, Euler was far from the first to publish an account of how to use mathematical notations to uncover truths about syllogistic forms systematically. His close friend Daniel Bernoulli ( $1700-82$ ) had published an essay in 1722 to show, in detail, how syllogisms can be demonstrated with mathematical precision by means of algebraic calculus. ${ }^{19}$ Long before then, Leibniz had worked extensively on logical calculus in tandem with his program of developing a universal characteristic. Although his numerous studies on logical calculus would remain unpublished for more than two centuries, his dissertation on the combinatorial art (Dissertatio de arte combinatoria, 1666 ) already contained germs for those studies. ${ }^{20}$ Also worth mentioning is the fact that Daniel Bernoulli's father, Johann Bernoulli ( $1667-1748$ ), who supervised Euler's study of mathematics, was among the first to fully understand Leibniz's differential (infinitesimal) calculus and had firsthand knowledge, through correspondence, of what

${ }^{77}$ Ueberweg, System der Logik, p. $216 . \quad{ }^{18}$ See Rescher, Galen and the Syllogism, pp. 22-35.

19 The essay in question is Theses Logicae ("Logical Theses") (1722). Sec especially $\$ \$ 6-10$, where Bernoulli analyzes propositions and syllogisms in extensional terms, in a way that anticipates Euler's analysis: e.g., a universal aftirmative proposition means the entirery of what is contained in the extension of the subject is also contained in that of the predicate, and a Barbana inference is valid in virtue of the axiom partem partis esse partem totins (part of part is part of whole). Another work worth mentioning is the Specimen logicae universaliter demonstratae (Specimen of Logic Universally Demonstrated) (Jena, 1740) by Johann Andreas Segner (1704-77), an influential mathematician and one of Eule's important cons Specimen is an attempt to establish the syllogistic by algebraic calculus, albeit with an intension 20 approach.

The unpublished studies include, among others, Specimen calculi universalis ("Specimen of Universal Calculus") from circa 1679 and Fundamenta calculi ratiocinatoris ("Fundamentals of the Calculus of

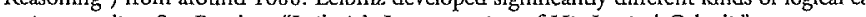
various studies. See Rescher, "Leibniz's Interpretation of His Logical Calculi," pp. I-13. 
Leibniz thought about its philosophical implications. ${ }^{2 r}$ It is impossible to determine how much of the Bernoulli-Leibniz exchanges might, at least by way of indirect influence, have shaped Euler's view on the relation between mathematics and logic or the power of the latter in calculating truths about reality. There is little doubt, however, that Euler developed his prooftheoretical use of the circle notation in an environment where many important German intellectuals were more or less familiar with the idea of logical calculus and the companion program of universal characteristic. Here is one way to put it: "while Leibniz's logical calculi themselves remained unknown, his seminal idea of logical calculus ... inspired later authors ... partly because it was anyway 'floating in the air' due to the atmosphere of the admiration for mathematics." ${ }^{22}$ In other words, if an eighteenth-century thinker could independently develop a logical calculus that resembled Leibniz's, it would be because that thinker, like Leibniz, was practiced in mathematics, understood its power, and had the acumen to "unify a variety of existing doctrines in a single system."

Indeed, the Germany of 1760 s witnessed critical developments in logical calculus, with Gottfried Ploucquet (I7I6-90) and Lambert (I728-77) as two major players. In 1763 , Ploucquet published two essays with telling titles: Methodus tam demonstrandi directe omnes syllogismorum species ... ope unius regulae ("The Method of Directly Demonstrating All Forms of Syllogism ... with One Rule") and Methodus calculandi in logicis ("The Method of Calculating in Logic") ${ }^{24}$ (a critical commentary on Leibniz's ars characteristica is appended to the latter). Lambert published the Neues Organon (New Organon) in 1764 and De universaliori calculi idea disquisitio ("Inquiry concerning the Idea of a Universal Calculus") in 1765 , dedicating both to a project of logical calculus that was closest to how Leibniz had envisioned it.

${ }^{25}$ Johann Bernoulli corresponded with Leibniz from 1694 through 1716 . Their correspondences were published in two volumes in 1745 (Leibnitii et Bernoullii Commercitum philosophicum et mathematicum, Geneva). Discussions of calculus and irs implications for the study of nature are

${ }_{22}$ especially abundant in the first volume.
Marciszewski and Murawski, Mechanization of Reasoning in a Historical Perspective, p. 117. The Marciszewski and Murawski, Mechanization of Reasoning in a Historical Perspective, p. 17 . The authors also mention Christian Wolff, whose agitation about pursuing logic with mathematical precision "helped to consolidate that state of consciousness which ultimately brought the perfect
rendering" of logical calculus (ibid., p. I 16 ). On the likelihood that Wolff had deep reasons for not rendering of logical calculus (ibid., p. I 16). On the likelihood that Wolft had deep reasons for not working out a logical calculus himself (such as pessimism about the prospect of finding a suitable to Kant "f thoughts), see Capozzi and Roncaglia, "Logic and Philosophy of Logic from Humanism 3 to Kant, P. I27.

24 A few years prior, Ploucquer alo, p. 133

Speculative Philosophy) (175g), published Frundamenta philosophiae speculativae (Fundamentals of to represen the quantity of concepts in inferences (Euler would use circles for basically the same purpose).
These works represent two fundamentally different approaches to logical calculus. Ploucquet denies the possibility of a universal calculus on the following grounds: since a calculus is in essence posterior to the understanding of the matter to which it is applicable (i.e., we must begin with considerations of beings), a single universal calculus is in principle out of reach for us, as it presupposes a kind of universal knowledge of things that should not be expected of us mortal beings. (It is still feasible, Ploucquet argues, to design multiple calculi for different domains of investigation.) For basically the same reason, mutatis mutandis, universal characteristic is also an impossible project for us. ${ }^{25}$

Lambert champions the opposite view in his Neues Organon. In part I of this two-volume monograph, the Dianoiology, or doctrine of the laws of thinking, Lambert analyzes the form of our thoughts in terms of both intension (Umfang) and extension (Ausdebnung), and uses both geometrical signs (lines) and algebraic ones (e.g., $=,>$ ) to represent relations of concepts in propositions and inferences (Dianoiology, $\$ \$ 1-78$, I I 8-93, 204-19). In part III, the Semiotics, or the doctrine of the designation of thoughts and things, Lambert introduces the idea of an artificial (symbolic) characteristic with explicit references to Leibniz's universal characteristic (allgemeinen Zeichenkunst) and extols algebra as a perfect paradigm thereof (Semiotics, $\$ \$ 33-9,54)$. He then envisions the companion project of a universal grammar (grammatica universalis) for the chatacteristic language, by which we can accurately analyze and represent our knowledge of things (Semiotics, $\$ \$ 70-101$ ). Lambert would work out further details of the algebraic calculus in the 1765 article just mentioned, where he would reaffirm his commitment to the ideal of universal logical calculus. ${ }^{26}$

This disagreement between Ploucquet and Lambert over logical calculus generated further exchanges about its direction, which were published in $1766 .{ }^{27}$ The details do not concern us here. What is worth pointing out is that Lambert would eventually acknowledge that universal calculus, insofar as it requires universal characteristic, might very well be like the philosopher's stone or the squaring of the circle. Here, then, is one way to conclude the Lambert-Ploucquet controversy: both sides came to see that the prospect of universal calculus was "hindered by a possibly insurmountable obstacle: the overpowering amount of philosophical analysis to be

25 Ploucquet, Metbodus calculandi, pp. 36-7 and 45-6. For further discussions, see Capozzi and Ploucquet, Methodus calculandi, pp. $36-7$ and 45-6. For further discussions, see Capozi
Roncaglia, "Logic," pp. 134-7; Marciszewski and Murawski, Mechanization, pp. I17-20. Roncaglia, "Logic," pp. 134-7; Marciszewski and Murawski, Mechanization, Pp. I17-20.
For further discussions of Lambert's logical calculus, see Capozzi and Roncaglia, "Logic," For further discussions of Lambert's logical calculus, see Capozi
pp. 137-41; Marciszewski and Murawski, Mechanization, pp. 120-9.

Pp. 137-41; Marciszewski and Murawski,
27 Bök, Sammling der Schriften, Pp. 157-256. 


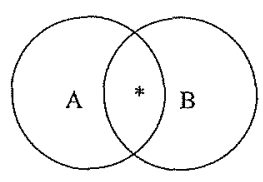

Figure 4. Some learned men are misers.

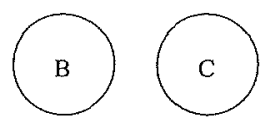

Figure 5. No miser is virtuous.

done in the fields of metaphysics, semiotics, and natural language to reach a suitable alphabet of thoughts."

Although the Ploucquet-Lambert controversy took place after the composition (but before the publication) of the Letters, the historical trend represented thereby gives us a useful perspective to appreciate the full meaning of Euler's proof-theoretical use of the circle notation. A close examination of this use will suggest his commitment to a modetate version of logical calculus.

To begin, Euler subscribes to the idea that the syllogistic can be proven by a few constant principles with mathematical precision. He identifies two such principles, to which " $[t]$ he foundation of all these [valid syllogistic] forms is reduced" and which concern "the nature of containing and contained": "whatever is in the thing contained, must likewise be in the thing containing," and "whatever is out of the containing, must likewise be out of the contained." ${ }^{29}$ By these principles, Euler uses circles both to demonstrate the is forms of perfect syllogisms and to show how to analyze the remaining 237 possible forms of syllogisms and prove them as fallacious. To illustrate the latter, consider this syllogism: "Some learned men are misers; no miser is virtuous; therefore, some virtuous men are not learned." By Euler's method, this inference can be disproved in three steps.

First, one represents the three terms by three distinct circles (more precisely, encircled spaces): circle $A=$ learned man, circle $B=$ miser, circle $C=$ virtuous man. The second step is to represent the logical relations expressed in the two premises with Figures 4 and 5 .

\footnotetext{
${ }^{28}$ Capozzi and Roncaglia, "Logic," pp. I 41-2. $\quad{ }^{29}$ Letter CIV, p. 464.
}

(a)

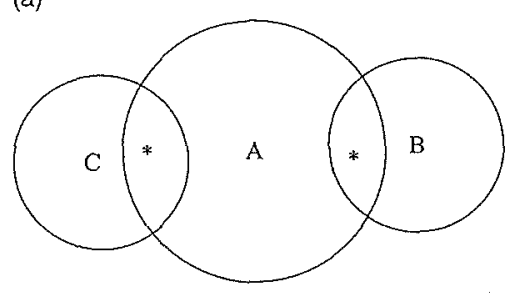

Figure 6.a.

(b)

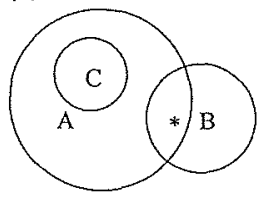

Figure 6.b.

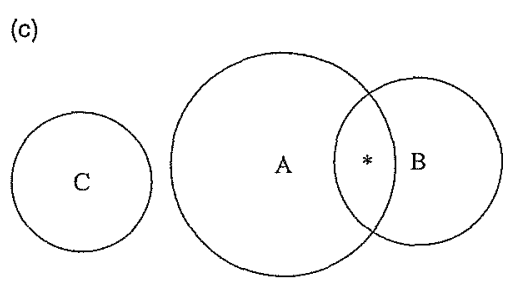

Figure 6.c.

The final step is to determine, by the aforementioned principles of the containing and the contained, what relation between encircled spaces $A$ and $C$ follows from the exhibited relations between spaces $A$ and $B$ (some part of space $A$ is in space $B$ ) and between spaces $B$ and $C$ (the whole of space $B$ is outside of space $C$ ). Euler stresses that the first relation concerns only the part of space A marked by ${ }^{*}$, which is contained in space B. It is certain that this. * part must lie outside of space $\mathrm{C}$, but how the remainder of $A$ relates to $C$ is thereby left undetermined. Euler illustrates three possible manifestations of the latter relation: partial containment (Figure 6.a), total containment (Figure 6.b), or total exclusion (Figure 6.c). As the given syllogism captures only the first possibility, it is invalid. ${ }^{30}$

${ }^{30}$ Letter CV, pp. 467-8. 
(a)

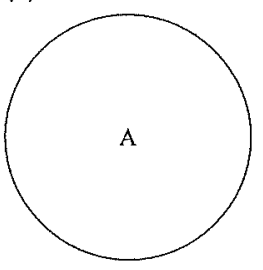

Figure 7.a.

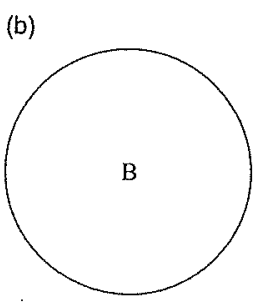

Figure 7.b.

This use of circles fits with Ploucquet's definition of "calculus in the generally accepted sense" as "the method of determining the unknown from known things according to constant rules." ${ }^{31}$ In Euler's own words, syllogisms are the means by which "from certain known truths, you attain others before unknown" and to which "all the reasonings ... may be reduced." To that extent, the syllogistic provides "the only method of discovering unknown truths." ${ }^{2}$ Thus, by using circles to represent propositions and demonstrate syllogisms, Euler has in effect submitted his own version of logical calculus. It has two components.

One component is an account of the procedure, previously outlined, by which any given syllogism may be proven valid or invalid. The other is a system of logical notations, together with rules governing their use, for the purpose of computing and drawing unknown truths from the known ones. Here is how Euler introduces his circle notation:

As a general notion contains an infinite number of individual objects, we may consider it as a space in which they are all contained. Thus [to represent the judgment all men are mortal,] for the notion of man we form a space [Figure 7.a] in which we conceive all men to be comprehended. For the notion of mortal we form another [Figure $7 . b$ ] in which we conceive everything mortal to be comprehended. (Letter CII, p. 453)

${ }^{31}$ Ploucquet, Methodius calculandi, p. 3 r. In a May 1678 letter to E. W. von Tschirnhaus (165I-1708), another important figure in the early developments of calculus, Leibniz defines calculus broadly as "operation through characters," which takes place in both counting and reasoning (Mathematische Schriffen von Gottfried Wilhelm Leibniz, vol. 4, p. 462). Notably, this they have in common. It does not restrict the project of logical calcul reasoning in terms of what they have in common. It does not restrict the project of logical calculus to the algebraization of all 32 reasonings, cven though the latter is its
${ }^{2}$ Letter CV, pp. $468-9$; CIV, p. 464.

This introduction of circles is premised on three claims (besides the obvious assumption of an extensional approach to the analysis of propositions and inferences). First, general notions are "the source of all our judgments and of all our reasonings." Second, general notions are formed by abstraction, each of which is "applicable to an infinite number of objects." Third, general notions can be represented by "signs," which serve as proxies for the denoted objects in thoughts and reasonings. ${ }^{33} \mathrm{~A}$ circle (as encircled space) is a sign in this sense, standing for a general notion by representing the objects it denotes. More precisely, Euler's circles signify general notions that occupy subject and predicate positions in propositions, for only then can they be used to represent various forms of propositions in accordance with different ways of arranging two encircled spaces in relation to each other.

We may employ, then, spaces formed at pleasure, to represent every general notion, and mark the subject of a proposition, by a space containing $A$, and the attribute [i.e., predicate], by another, which contains $B$. The nature of the proposition itself always imports, either, that the space of $A$ is wholly contained in the space $B$, or that it is partly contained in that space; or that a part, at least, is out of the space B; or, finally, that the space $A$ is wholly out of B. (Letter CIII, pp. 454-55)

In this way, circles may be used as what Lambert calls "scientific" signs, which "not only represent those concepts and things in general but also display [anzeigen] relationships, so that the theory of a thing [Sache] and the theory of its signs can be interchanged." 34

That being said, we do not have enough textual materials to press further and figure out Euler's exact attitude toward the overall project of logical calculus that exercised some of the best minds of his time. ${ }^{35}$ For the purpose of this paper, it suffices to see his proof-theoretical use of the circle notation as one among many passages in the history of logical calculus between Leibniz and Kant. This historical connection, along with the supposition that Euler's circle notation was the most likely source of Kant's, makes one wonder about the philosophical relevance of the latter.

${ }^{33}$ Letter CII, pp. 450-1. $\quad{ }^{34}$ Lambert, Netres Organon, Semiotics, \$23.

${ }^{35}$ I suspect that Euler's position would be like Ploucquer's: no Leibnizian style of universal language is needed to apply his logical calculus. The Leibnizian idea of universal characteristic presupposes an intensional treatment of concepts, according to which each complex concept can be analyzed and ulrimately reduced to a combination of atomic ones. Euler's circles, by contrast, stand for general notions with respect to exension, which comprises the multitude of objects falling under each not rever 


\section{Kant's Circle Notation: From Logical Calculus to Logical Formality}

Kant foresees the fate of the Leibnizian idea of universal logical calculus in his 7755 text $A$ New Elucidation of the First Principles of Metaphysical Cognition. He compares Leibniz's pronouncement of the ars characteristica combinatoria (art of combining signs) to the will of the dying father in one of Aesop's fables, who tells his children about a hidden treasure somewhere in his field without saying exactly where.

This [announcement of the father] induced the sons assiduously to turn up the field and work it over by digging up, until, their hopes disappointed, they nonetheless found themselves certainly enriched by the fertility of their field. I suspect, at any rate, that this will be the only fruit, to be sure, which an examination of that celebrated art will yield, should there be anyone prepared to devote themselves to the execution of this task ... For my own part, I do not deny that, once one has arrived at absolutely first principles, a certain use of the art of signs may be legitimate, for one has the opportunity there of employing the concepts and consequently the simplest terms, as well, as signs. (NE, I:390, my emphasis)

These remarks suggest that Kant is aware of the difficulties associated with the Leibnizian program of designing a universal characteristic in terms of which to analyze all human cognitions for the sake of computation, without which there would be no universal logical calculus. If he grants some utility to a logical calculus, he does so with a caveat: it is not a tool for discovering previously unknown truths, but at best a way to present truths once they bave been discovered on independent grounds. ${ }^{36}$ To some extent, this caveat anticipates Ploucquet's aforementioned argument that the design of a feasible logical calculus must be posterior to knowledge of the relevant domain of inquiry.

For Kant, the fundamental limitation of logical calculus has to do with the very nature of logic. On his account, logic is not "a universal art of discovery" or "an algebra, with whose help hidden truths can be discovered." ${ }^{37}$ He makes a similar point by distinguishing organon (instrument or tool of discovery) and canon (criterion or standard for assessment). A logic, such as Lambert's, that purports to be the organon for particular sciences such as mathematics and physics professes to offer the "directive as

${ }^{36}$ Kant goes on to illustrate how proofs by means of calculus involves "an indubitable begging of the
question" (NE, $\mathrm{x:3}$. question (NE, $\mathrm{x}: 390)$

37 JL, 9:20; see JL, 9:I3, 16; LV, 24:793. to how a certain cognition is to be brought about." ${ }^{38}$ In Kant's view, logic (properly so called) can never fulfill this promise. Rather, it is strictly concerned with the mere form of thought and so can only supply the "principle of the assessment, not of the construction, of cognition." 39

Hence, if Kant allows that circles, squares, and the like may be used to represent logical relations, his use of such notations will have no real affinity with the project of logical calculus, as Euler's did by some measures. Nor will Kant see the need for a single procedure to prove the traditional syllogistic, which I mentioned as a possible motivation for Euler's adoption of the circle notation. In The False Subtlety of the Four Syllogistic Figures ( $1762-3$ ), Kant posits two highest principles by which to prove valid syllogisms in the first figure, namely "a characteristic mark of a characteristic mark is a characteristic mark of the thing itself" and "that which contradicts the characteristic mark of thing, contradicts the thing itself." (Note that these principles are formulated in intensional terms.) As for syllogisms in the remaining figures, they must be transformed, through a logical conversion or contraposition of one of their premises, into the first figure before being examined in accordance with the aforementioned principles. ${ }^{40}$ Whether Kant is right on this point is a separate issue. The important thing to note is that, while using circles to represent certain relations of terms in syllogisms, he is not thereby getting on board with the project of proving syllogisms as valid or invalid by means of geometrical figures plus the rules governing their relations. Circles can serve only to exhibit the relations in a given syllogism, the validity or invalidity of which must be established on independent grounds.

What, then, are we to make of Kant's use of the circle notation? My hunch is that, when coupled with his conception of logical formality, the same notation now has a different meaning - to the point where the circles will be totally dislodged from the project of logical calculus.

To flesh out this hypothesis, it will be instructive to begin with a brief account of Kant's notion of logical formality. In the preface to the secondedition of the Critique of Pure Reason, Kant defines logic as "the science that exhaustively presents and strictly proves nothing but the formal rules of all thinking (whether it be a priori or empirical, whatever origin or object it may have, and whatever contingent or natural obstacles it may encounter in our minds)." This definition, together with the ensuing clarification that logic abstracts "from all objects of cognition and all the distinctions

${ }^{38} \mathrm{R}$ 1629, $16: 48 ; \mathrm{JL}, 9: \mathrm{x}_{3} ;$ see A52/B76. ${ }^{39} \mathrm{R} \pm 6 \mathrm{x} 2,16: 36 ; \sec \mathrm{A60-2} / \mathrm{B} 84-6$ ${ }^{40} \mathrm{FS}, 2: 49-54$. 
between them," signals three aspects of logical formality as Kant construes it. That is, logic is formal insofar as it abstracts (a) from the contingent empirical conditions of the thinking subject, (b) from all differences among the objects of thinking, and (c) from whether or how (viz., a priori or empirically) our thoughts may refer (beziehen) to the objects. ${ }^{4 \mathrm{I}}$

Clause (c) captures Kant's claim that formal logic treats thinking in abstraction from all reference to objects. This is not to say that logic treats thoughts as though they are nonintentional. The point, rather, is that logic abstracts from the nature of their purported objects, and especially from whether or how they may be given to us. Kant often presents such abstraction as the setting aside of considerations about the matter of cognition: "Logic is then a science of the form of understanding and reason in general. Universal logic must abstract from all objects ...; thus logic exhibits the form, without being concerned with the matter (LW, 506)."142 This abstraction from the matter of cognition, in turn, is connected with Kant's view that logic "cannot be an organon of the sciences ... because an organon presupposes exact acquaintance with the sciences, their objects and sources." On the contrary, logic is none other than the "universal propaedeutic to all use of the understanding and of reason in general" and, as such, "may not go into the sciences and anticipate their matter." 43

This account of logical formality gives us the precise framework within which to analyze Kant's adoption of the circle notation and to appreciate its philosophical significance. Like Euler, Kant uses a circle to represent the logical extension (Umfang) or sphere (sphaera) of a concept, which comprises the multitude of things to which it is applicable: "The multitude of things [Dinge] that are contained under the concept is called the logical sphaera of the concept ... We understand by that ... the circle of application, a line that has in itself no breadth but nonetheless comprehends a great space" (LDW, 24:755). Every concept treated in logic has a logical extension simply by virtue of being a concept, for logic "deals only with concept as concept," that is, only in view of its "logical form," which lies in its being "common to many." 44 "The sphaera notionis means

${ }^{41}$ Bviii-ix; see A55-6/1379-80. I discuss these aspects of Kant's notion of logical formality in Lu-Adler, Kant's Conception of Logical Extension, ch. I.

42 Throughour his logic corpus, Kant often speaks of "content," "matter," and "object" of cognition without distinction and conrrasts them equally with the form of cognition. See LDW, 24:693; LB, 24:25; LV, 24:792; R $1698,16: 87$

24:25; LV, 24:792; R
43 JL, 9:13; see A $52 / \mathrm{B} 76$.

+ $\mathrm{LPö}, 24: 567-8$. The form of a concept is its generality, i.e, its ability to represent what is common to multiple objects (JL, 9:9r; LV, 24:904, 908). actually the multitude of things [Dinge] that are comprehended under a concept as a nota communis" (LB, 24:257; see LPh, 24:454).

If Ding in this context means abject, then the logical extension of a concept represented by a circle is the multitude of all the possible objects falling under a given concept. Insofar as the concept is treated in view of its generality, which is its essential logical character, its logical extension is always a multitude (even if, in reality, no object falls under the concept, so that it is empty in terms of real extension). ${ }^{45}$

When two concepts in a (categorical) judgment are treated in extensional terms, the logical form of the judgment can be interpreted as a relation between the concepts in respect of their logical extensions.

If the sphere of the subject is entirely contained in the notion of the predicate or is considered entirely outside it, then it is a universal affirmative judgment in the first case and a universal negative judgment in the last case ...

If the sphere of the subject partly falls in that of the predicate, and partly does not, then it is particular judgment ...

With all judgments I compare nothing other than the spheres of concepts and see whether one is contained in the other or not. (LPh, 24:463)

Using two distinct circles to signify the logical extensions of both the subject and the predicate of a judgment, Kant can then represent the four basic forms of categorical judgments by four possible arrangements of two encircled spaces in relation to each other (Figures 2.a-2.d). The relations are described in such terms as "partly" versus "entirely" and "in" versus "outside."

On the surface, this use of circles resembles Euler's. There is a fundamental difference between the two, however, which comes down to how the objects that constitute the extension of a concept are construed.

When Euler uses circles to represent general notions in judgments and inferences, and thereby treats each notion as applicable to an infinite number of individual objects, the objects are assumed, to borrow the familiar Kantian terminology, as what can in principle be given to us in experience. General notions supposedly differ from "sensible ideas, which represent to us objects really existing" (i.e., objects as are immediately present to our senses), and thereby allow us to talk about objects without having any particular objects in mind. ${ }^{46}$ For those notions are formed by abstraction, which "takes place when the soul fixes its

45 I defend this objectual reading of Kant's logical extension in Lu-Adler, Logical Extension, ch. 2. ${ }^{46}$ Letter C, pp. 442-4. 
attention on only one quantity or quality of the object, and considers it separately, as if it were no longer attached to the object." 47 Sense perceptions of actual particulars are still the ultimate source of general notions, however. To that extent, in terms of denotation, these notions do not go beyond the realm of reality or existing individuals. Here is how Euler puts the point:

With respect to general notions, every existing object, comprehended under one, is denominated an individual, and the general idea, say that of the cherry-tree, is denominated species or genus ... Thus the notion of a tree may be considered a genus, as it includes the notions of pear-trees, apple-trees, oaks, fire, and so on, which are species; and of so many others, each of which contains a great number of existing individuals. (Letter $\mathrm{C}$, p. 444)

Hence, if William Hamilton is right to characterize Euler's circles as means for "sensualizing ... the abstractions of logic," 48 for Euler they are also means of representing reality. This representational character of the circle notation presumably underlay his confidence that the logical calculus constructed with the notation could serve for the discovery of all truths. In that connection, the abstractions sensualized by circles are meant only to ensure the greatest generality of what they represent. Such abstractions may be called "empirical abstractions," as they merely set aside particularities of the objects as we experience them.

Prima facie, Kant has a similar sense of abstraction in mind when he explains how logic, dealing with the mere form of cognitions (including concepts), addresses the question: "Which acts of the understanding constitute a concept? or what is the same, Which are involved in the generation of a concept out of given representations?" On his account, a concept as to its form qua general representation is "always made" and is "grounded on the spontaneity of thinking," i.e., on the capacity of the understanding to "transform" given representations into concepts. Abstraction is among the "logical actus of the understanding" that constitute "the essential and universal conditions for the generation of every concept whatsoever [as regards its form]." Kant mostly uses empirical concepts (such as tree) to illustrate this account of the "logical origin" of concepts. ${ }^{49}$

This account, however, does not require that the representations over which the logical act of abstraction is exercised be traceable to our sensible representations of existing objects. Rather, as far as formal logic is

47 Ibid., p. $441 . \quad 4^{8}$ Hamilton, Lectures on Logic, vol. I, p. 256.

49 JL, 9:93-5; see A68/B93; A76/Broz; LPö, 24:566; LV, 24:907-10. concerned, it "expects that representations will be given to it from elsewhere, whatever this may be." Tho This abstraction from the source of representations separates the so-called general logic from transcendental logic: if the latter treats our cognition only insofar as it is related to objects a priori, the former "abstracts ... from any relation [Beziehung] of it to the object."

[General logic] considers representations, whether they are originally given a priori in ourselves or only empirically, merely in respect of the laws according to which the understanding brings them into relation to one another when it thinks, and therefore it deals only with the form of the understanding, which can be given to the representations wherever they may have originated. (A56/B80)

This abstraction from the origin of representations corresponds to the third aspect of Kant's notion of logical formality mentioned previously: (general) logic is formal in that it treats thoughts in abstraction from whether or how they relate to their purported objects. Here we have a kind of transcendental abstraction, namely abstraction from whether our thoughts are related to any possible objects of experience at all. The result of this abstraction is what Kant calls "the concept of an object in general [überhaupt]" $(x)$, which is the "highest concept of the whole human cognition" independent of whether the object conceived is possible or impossible. ${ }^{5 x}$

In that connection, if Kant uses circles to represent the logical extensions of concepts in judgments and inferences, with the extension of each concept comprising the objects falling under it, he means by "object" merely an object in general $=x$, which signifies the same general-logical realm for all concepts. It is in terms of this notion of object that Kant characterizes the logical schema of every judgment:

[A]n object is only a something in general [ein Etwas ïberbaupt] that we think through certain predicates that constitute its concept. In every judgment, accordingly, there are two predicates that we compare with one another, of which one [a], which comprises the given cognition of the object $[x]$, is called the logical subject, and the other $[b]$, which is to be compared with the first, is called the logical predicate. (R $4634,17: 616)^{52}$

The described schematic relation between two concepts in a judgment is captured by Figure 8:

5o A76/Bro2, my emphasis. $\quad{ }^{51} \mathrm{ML} 2,28: 543 ;$ see A290/B346; MMr, 29:81 1; MVi, 29:960-r ${ }^{52}$ See R 3920, 17:344-5; R 3921, 17:345-6; R 4676, 17:653-5. 


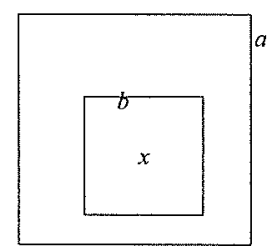

Figure 8. Relation between two concepts in a judgment.

Here, the squares $b$ and $a$ represent the logical subject and predicate of the judgment, respectively, and the letter $x$ marks whatever object lies within the logical extension of the subject. ${ }^{53}$

By thus interpreting the general-logical realm of objects in terms of the object in general $=x$, Kant has limited the meaning and utility of the circle notation. In sum, as circles are used in formal logic, they serve simply as means to sensualize the abstraction of logic in its highest form, representing concepts independent of whether or how they may refer to the objects of possible experience. To the extent that such references alone could give real meaning to our concepts and the judgments and inferences composed from them, the circles that represent abstractions from such references are entirely detached from the project of logical calculus for discovering (material) truths. ${ }^{54}$

\section{Conclusion}

Now let us return to Venn's conjecture that the lack of progress in mathematical logic between Lambert and Boole was due to Kant's "disastrous effect on logical method." Kant's philosophical reflections on the nature of logic might very well have had the alleged effect. In general, I find it extremely hard, if not entirely unproductive, to speculate about historical consequences of a philosophical theory. Nonetheless, if my contextualized account of what he did with Euler's circles is on the right track, it suggests that Kant's aim was not so much to discourage his audience from developing suitable mathematical devices for logical use altogether as to clarify what, exactly, such devices could be used to achieve. Without such clarification, he might add, all efforts at introducing mathematical notations into logic would be blind if not a complete waste of time.

53 R 3096, 16:658; JL, 9:108.

44 The circle notation may still be useful for uncovering what I call "formal truths" (of Kantian analytic judgments). Sec Lu-Adler, "The Objects and the Formal Truth of Kantian Analytic Judgments."
As his adoption of the circle notation indicates, Kant is open to using mathematical notations to represent the relations of concepts in judgments and inferences - but only after having peeled off, so to speak, the features once attached to those notations as part of the Leibnizian logical calculus. That is, we may utilize mathematical notations in logic so long as we do not thereby assume that all our complex thoughts can be fully analyzed and symbolized by means of a universal characteristic or that we can employ a logical calculus to discover previously unknown truths (in the material sense). We may think more precisely with the help of mathematical notations, but such increased precision amounts only to a formal improvement - as opposed to a material extension - of our cognition..$^{55}$

As for Euler, I ascribe to him a modest version of logical calculus. In his view, to the extent that a judgment can be derived as the conclusion of a syllogism with two known premises, we can reveal its truth by using circles to represent all the involved concepts - more precisely, to represent the objects signified thereby - and then computing their relations in accordance with the basic principles governing the containment relations among encircled spaces. If Euler deemed this "the only method of discovering unknown truths," Kant could agree with him, as long as "unknown truths" meant truths of which previously we were not clearly aware. But this caveat would only reinforce Kant's point that by a logical calculus we can at best increase the formal perfection of our cognition, without thereby learning anything new in the material sense.

Kant thus brings home the view that the means provided by formal logic at best help us express and somehow order what we already know. No matter how much mathematical notation may enhance the precision of this function of formal logic, it does not change the fact that no truths can be proven strictly by means of that notation. One would have misunderstood Kant, however, to infer from this claim a total resistance to the use of mathematical tools in formal logic. The claim is, rather, a cautionary note against misuse of such tools to do what they cannot do, namely to discover new truths.

ss Kant sometimes uses such notations as + to represent the relation between the logical subject and predicate in an analytic judgment: "An example of an analytic proposition is, To everything $x$, to which the concept of body $(a+b)$ belongs, belongs also extension $(b)$ (J), 9:I I I). If this symbolization of the concepts body" and "extension" helps us to see more clearly their intensional containment relation, the relation iself is only expressed but nor discovered by dhe symbolic mens, since how we choose to symbolize each concept already presupposes prior knowledge of its intensional content. For further
discussion, see Lu-Adler, "Objects and Formal Truth." 